\title{
Five "C's" of successful startups
}

\section{Maintaining the balance of commitment, communication, criticism, conjecture, and competition is the basis for bioentrepreneurial success.}

\section{James C. Blair}

Having had the good fortune of being among the pioneering venture capital investors in the biotechnology industry, the most striking thing to me about biotech startups-at least of the 75 or so I've helped launch-is that all of them have had to modify their original business plans in order to survive. Because of ever changing technical, regulatory, and financing environments, bioentrepreneurs must necessarily be more adaptive than most of the rest of the world. Obviously, this process of modifying a business so that it fits its environment can produce a high degree of stress between the scientific founders and their financial backers if not managed well. Many times the difference between abysmal failure and phenomenal success can be traced to precisely this ability-or inability-to adapt.

For this reason, any bioentrepreneur shopping for a financial partner-venture capital or otherwise- should carefully examine five key issues before agreeing to enter into such a marriage. These can be summarized as the five "C's": commitment, communication, criticism, conjecture, and competition. Understanding both your own and your financial partner's capacity to deal with each of these elements will establish the basis for successfully growing your business.

\section{Long-term commitment}

There is no single element that fractures the relationship between founder and venture investor faster than the sense that the investor is only there for the quick reward. Commitment to staying the course is perhaps the most important contribution your VC can provide.

I was first taught this lesson by my New Court Securities (New York) mentor, Charlie Lea. New Court was an original venture capital backer of Federal Express (Memphis, TN), the company founded on the vision of Fred Smith. Despite the fact that this company is a tremendous success

James C. Blair is a general partner at the venture capital firm of Domain Associates, One Palmer Square, Princeton NJ 08542

(blair@domainvc.com).

\section{Because of changing technical, regulatory, and financing environments, bioentrepreneurs must be more adaptive than the rest of the world.}

today, it came within two months of failure as it struggled to become fully operational. Charlie spearheaded financing efforts three times, totally recapitalizing it twice following its initial financing. The last financing provided the company with only two months of operating cash, but those two months of cash permitted the company to attain profitability and prove that Fred Smith's dream was based on sound operating concepts.

Later on, I had the chance to emulate my mentor in dealing with a private company named Immunetech Pharmaceuticals. We already had invested an amount that was well over our comfort level while we waited for the Food and Drug Administration (Rockville, MD) to approve an allergy therapeutic for which a new drug application had been submitted three years earlier. When the company's management identified a small respiratory-focused marketing company that it wanted to acquire, we gulped hard, and agreed to put up the additional financing necessary to effect that acquisition. The resulting company evolved into what is now Dura Pharmaceuticals (San Diego, CA), which has produced better than 50-fold returns to our investors.

Both stories illustrate that venture financing is a long-term business. There can be no expectation of instant gratification for either the founders or investors. Therefore, pick your partners well, as both groups need to be willing to hang in there.

\section{Communicate often and openly}

All of our best investments have been characterized by outstanding communication at all organizational levels. While other factors may doom an ill-fated venture, an otherwise good company will suffer significantly without free flowing communications.

Amgen's (Thousand Oaks, CA) founder, George Rathmann, had a knack for promoting communication between groups that ordinarily did not talk. In the early days at Amgen, George would have his scientists display posters at their lab benches so they could be prepared to deliver ad hoc presentations on their activities to the business types who wandered through the labs. This turned out to be a highly effective method for bonding scientists and business people together over the company's technical direction. As a result, George developed a reputation among scientists as a businessman, and among businesspeople as a scientist.

This same principle can be applied vertically within companies with great success. We've found that often the best way to find out where the creativity exists within a talented organization is to present the problem to as many people as possible, and then see what emerges. Not uncommonly, the problem may be solved by a person or group that normally wouldn't have been asked the question.

This is especially true when news isn't very good. It has been our experience that the people who work for biotechnology companies are highly intelligent to begin with, and don't need a lot of spin control on the information that flows their way. They like to know everything that's going on and develop a much greater commitment to a company that is straightforward in delivering information about its ups and downs.

This same philosophy holds true for the communication between a company's officers and its investors-venture or public, as the case may be. There is no faster way to lose the confidence of one's investors than to attempt to trivialize problems.

Open communication can be one of the greatest assets a partnership can have. Whether it is between management and investors or management and employees, it creates a culture of trust and support that will carry you through the crises you will undoubtedly experience. Communication is one of the few things that is habit forming and is not dangerous to your health. 


\section{Critique your strengths and weaknesses}

Most scientific groups do a reasonably good job of explaining the benefits of their particular approach. But very few of these groups have thought out alternative methods of applying their strengths, or to put it another way, the implications of their weaknesses. Bioentrepreneurs should embrace prospective investors who spend a fair amount of time probing and defining the weakness in a specific technical approach. Often, these early examinations are the key to long-term success.

This was the case when my firm was doing its initial evaluation of a startup investment in Trimeris (Research Triangle Park, NC)-a company built around Dani Bolognesi's research on HIV at Duke Medical School (Durham, NC). At the outset, there seemed no compelling reason to start what had to be the fiftieth AIDS company. It wasn't until we were much further into the discussions that Dani was able to emphasize the broad applicability of this approach to the development of other antivirals. Trimeris now has what appears to us to be a highly promising AIDS drug in the clinic, as well as an exciting platform for further drug discovery: A potential weakness was turned into a strength.

Another weakness of most biotech startups is their belief that their scientific capabilities are somehow vastly superior to those of the rest of the world. I've always believed that this "Not Invented Here" mentality has no place in a commercially focused scientific organization. The best rebuttals to this notion were demonstrated by Amgen's early decisions to collaborate with University of Cincinnati scientists on the EPO gene, and later with Memorial Sloan Kettering scientists on G-CSF. Contrary to some opinions that these collaborations reflected weak science at Amgen, these decisions were directly responsible for Amgen's market leadership position today. Fortune is the result of the marriage of preparedness and opportunity. In Amgen's case, fortune evolved directly from a group of self-confident scientists who were prepared to accurately appraise their strengths and needs.

Work with people who will challenge your thinking and question your assumptions. Attaining scientific leadership in a specific area is one thing; sustaining industry-wide leadership in a therapeutic area requires total intellectual honesty.

\section{Eliminate conjecture: Perform the "killer" experiments early}

There are many lessons I have learned the hard way in my years as a venture capital investor, and most of them I only needed to learn once. The one that seems to resurface most often concerns early validation of critical scientific assumptions. The reason for this is clear. When the bioentrepreneur leaves his or her job at an academic or clinical institution to start a new venture, the last thing they want to do is determine that the scientific hurdles before them in commercializing their technology are insurmountable. So after they are funded, too much time is spent hiring full-time staff, building new lab space, and putting in place other elements of infrastructure before the critical "killer" experiments are done.

Establishing a "virtual company" designed to attack these gut questions early on is one way around this. Since all of the early money is spent on answering the tough questions rather than building infrastructure, nobody gets more than a nicked ego if the key answers don't come out the way everyone hoped. Most venture firms active in life science investing now have excellent incubation facilities for nonlaboratory work, and most universities and clinical research centers

\section{Contrary to most bioentrepreneurs' gut reactions, it is a good thing for your company when your competitors are doing well-unless, of course, their success comes at your expense.}

are happy to establish cooperative research arrangements. Though it may sound selfserving, we believe that if a technology doesn't work, it's better for everyone to find this out at a cost of $\$ 2$ million rather than at a cost of $\$ 20$ million.

Sometimes, however, dealing with the "killer" question may not be a scientific issue. For example, it could also be the ability to license a key patent or to secure a volume manufacturing source of starting materials. In these cases too, the money should be spent to answer the questions before building the infrastructure.

The best policy is always to ask the toughest questions you can about what you are doing, and then embrace a process which will get you the answers.

\section{Respect your competitors}

Contrary to most bioentrepreneurs' gut reactions, it is a good thing for your company when your competitors are doing wellunless, of course, their success comes at your expense. If the world thinks your competitors are on the wrong track, they sure can't think much of what you are doing! If your competi- tor has done something well, learn from it. Perhaps one of the best (or worst) examples of this occurred when the two champions of antisense technology-Genta (San Diego, CA) and Isis (Carlsbad, CA) — simultaneously went on the road to effect their initial public offerings. Each company was less than complimentary when asked questions about the other's technology. This left prospective investors confused about the real value of the technology and each company's respective position in the field.

It is equally important to emphasize the pitfalls of being a follower. In the early days of the life science industry, the conventional wisdom was that those companies concentrating on agricultural products, diagnostics, or industrial chemicals had the best chances for success because regulatory battles for product approval would be less severe in those areas. A major consulting study from Arthur D. Little confirmed this wisdom.

Most of the recombinant companies which had been formed had a fishing license for all of these ponds, and conversations at a number of board of directors meetings I attended centered on where the fish seemed to be biting. The measure of success seemed to be who was getting which corporate nibbles in which areas. When companies such as Amgen, Centocor (Malvern, PA), and Genetics Institute (Cambridge, MA) started to narrow their focus and concentrate on human therapeutics, this was perceived as risky, because it was counter to the accepted view. In retrospect, you would be hard pressed to remember many of the leading companies of that period who chose not to focus on therapeutics, despite their clear successes at the time. Genex developed what is now Searle's leading sweetener product, but failed as a company. Cetus was the early champion of industrial chemicals, but was later merged with Chiron (Emeryville, CA) to develop treatments for cancer and immune system disorders.

The real lesson to be learned here is that most scientifically strong companies will find their competitive niche if they can both respect the achievements of their competitors, and yet not attempt to follow them.

\section{Conclusions}

Bioentrepreneurs today have the great advantage of being able to follow a trail blazed during the past quarter century. To be sure, this is a path fraught with stress. However, it is possible to convert that stress into a positive source of energy within a developing biotechnology business if one is ever vigilant in maintaining the five "C's" as the platform from which to adapt. Using this platform to choose a venture firm is the first step to building a partnership that will last and succeed. 